\title{
Adrenocortical Atrophy and Diffuse Cerebral Sclerosis
}

\author{
CONSTANCE C. FORSYTH, MEHROO FORBES,* and J. N. CUMINGS \\ From the Department of Child Health, University of Dundee; and the Department of Chemical Pathology, Institute of \\ Neurology, The National Hospital, London
}

\begin{abstract}
Forsyth, C. C., Forbes, M., and Cumings, J. N. (1971). Archives of Disease in Childhood, 46, 273. Adrenocortical atrophy and diffuse cerebral sclerosis. A boy, diagnosed as having Addison's disease due to idiopathic atrophy of the adrenal glands at the age of 7 years, developed the first evidence of what was originally thought to be 'Schilder's disease' at 8 years and 10 months. He died at 9 years and 11 months. There was a very striking family history of autoimmune disorders on the mother's side. The clinical and pathological aspects of his case are outlined. Detailed studies of adrenal function during life showed a diminution in excretion of adrenal androgens and corticosteroids before therapy which was not evident from the 17-oxosteroid and 17-hydroxycorticosteroid assays in the resting state, though the initial diagnosis was based on the failure of ACTH to produce a rise in the 17hydroxycorticosteroid excretion. No unusual or abnormal steroids were detected nor was there any disproportion between the androgen and corticosteroid excretion to suggest an adrenal enzyme deficiency. The biochemistry of the brain at necropsy revealed the changes expected in a demyelinating disorder, but the detection of abnormalities in the grey matter distinguished the condition from 'Schilder's disease' in which the biochemistry of the grey matter is normal. There are 12 fully documented reports of boys with adrenocortical atrophy and diffuse cerebral sclerosis, and it is thought that this rare entity is inherited as an X-linked recessive characteristic. The two likely theories of causation involve either an error of metabolism common to the adrenal cortex and the brain, or the possibility that both the adrenal and brain pathology are due to an autoimmune disorder.
\end{abstract}

There are 12 fully documented reports of boys with the combination of adrenocortical atrophy and diffuse cerebral sclerosis (Siemerling and Creutzfeld, 1923; Pfister, 1936; Gagnon and Leblanc, 1959; Lichtenstein and Rosenbluth, 1959; Brun and Voigt, 1960; Hoefnagel, Van den Noort, and Ingbar, 1962; Fanconi et al., 1963; Blaw et al., 1964; Dubois et al., 1964; Turkington and Stempfel, 1966; Gordon and Marsden, 1966; Hoefnagel et al., 1967). Case histories of 2 boys have been published also with incomplete pathological data (Pfister, 1936; Adams and Kubik, 1952). The report on our patient includes comments on the assays of individual urinary steroids and on the biochemistry of the brain.

\section{Case Report}

This boy (J.F.) was born on 2 January 1957 by caesarean section at 36 weeks' gestation, birthweight

Received 24 August 1970.

^Present address: Department of Pathology, The Children's Hospital, Western Bank, Sheffield 10.
$2 \cdot 7 \mathrm{~kg}$. The pregnancy was normal but there was a history of 8 previous miscarriages. He thrived well. When he was 2 years old his mother first noticed mild pigmentation of the skin and it reminded her of the pigmentation shown by her brother, who had died of Addison's disease. Her son's health, however, remained very good, and though he had mumps, measles, chickenpox, and a tonsillectomy, he was never seriously ill until at the age of 6 years and 9 months he contracted Sonne dysentery and required intravenous therapy.

A slightly low plasma sodium level was noted and because of the skin pigmentation and family history of Addison's disease an ACTH test was done. ACTH gel was given intramuscularly in a dose of 20 international units twice daily for three days. The 17-hydroxycorticosteroid result on the day before ACTH was $8 \mathrm{mg} / 24 \mathrm{hr}$ and the highest level reached during ACTH and on the day after was $7.5 \mathrm{mg} / 24 \mathrm{hr}$. While the results were awaited, the boy returned to school, but a month later in January 1964 at the age of 7 years (Fig. 1), he developed a sore throat with associated vomiting. He was given intravenous therapy but hydrocortisone was withheld at this stage. A 24-hour urine collection was made. A week later, when he had 


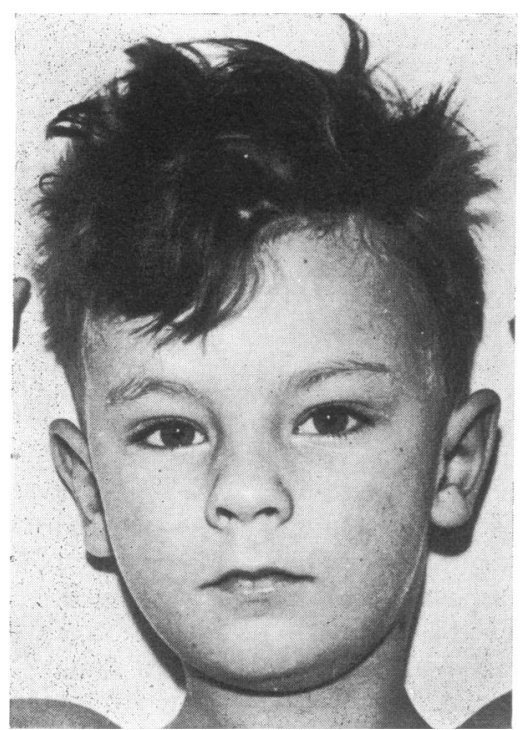

FIG. 1.-J.F. aged 7 years.

fully recovered from the throat infection, a second ACTH test was done, using the same dosage but a different batch of ACTH. On this occasion the resting level of 17-hydroxycorticosteroids was $5 \cdot 7 \mathrm{mg} / 24 \mathrm{hr}$ on the day before ACTH was given, and the highest level reached during the test was $6 \cdot 1 \mathrm{mg} / 24 \mathrm{hr}$. It was of interest that the urine collected during the first 24 hours of admission when he was very ill, gave a 17hydroxycorticosteroid output of $10 \mathrm{mg} / 24 \mathrm{hr}$, considerably higher than that reached by artificial stimulation of the adrenal gland with ACTH during the ACTH tests. It was considered that though the resting levels of 17-hydroxycorticosteroids were within normal limits for a boy of his age, his response to the two ACTH tests and to natural stress was inadequate. In normal children an ACTH test carried out in this manner leads to a rise of total 17-hydroxycorticosteroids to $20 \mathrm{mg} /$ $24 \mathrm{hr}$ at least (Clayton, Edwards, and Renwick, 1963). It was not possible to estimate the excretion of aldosterone locally but the adrenal medullary function was checked. The noradrenaline excretion was $19.8 \mu \mathrm{g} /$ $24 \mathrm{hr}$, the adrenaline $3.6 \mu \mathrm{g} / 24 \mathrm{hr}$, and the vanillyl mandelic acid (VMA) was $2 \cdot 5 \mathrm{mg} / 24 \mathrm{hr}$. All three were considered to be within normal limits. There was no evidence of tuberculosis of the adrenal glands. In view of the possibility of autoimmune disease, the boy's serum was tested by the complement-fixation method and the immunofluorescence method for adrenal antibodies by Professor J. Anderson in Glasgow, and it was negative. His mother's blood was similarly tested and was negative. The boy's blood and his mother's blood were also tested for thyroid autoantibodies and proved negative. There was no evidence of disease of other endocrine glands, e.g. the pituitary, the thyroid, the parathyroids, the pancreas, or the testes. The chromosome pattern was that of a normal male. Clinical examination of the central nervous system was negative. A skull $x$-ray revealed no abnormality and the EEG was reported by Dr. P. Aungle as within normal limits.

It was thought that the boy suffered from idiopathic adrenocortical atrophy. In spite of the absence of adrenal antibodies in the circulating blood, an autoimmune causation was suspected because of the strong family history of autoimmune disorders among the mother's sibs (Table I). The family history on the father's side was negative for endocrine and neurological disease. He was treated with cortisone and fludrocortisone and made excellent progress though the skin pigmentation never completely disappeared. He attended school regularly for 17 months.

TABLE I

J.F.-Mother and her Sibs

\begin{tabular}{|c|c|c|}
\hline Mother & $\begin{array}{l}\text { Thyrotoxicosis, rheuma- } \\
\text { toid arthritis }\end{array}$ & Temporary drug \\
\hline Sister & Thyrotoxicosis & Thyroidectomy \\
\hline Brother & $\begin{array}{l}\text { Addison's disease, no } \\
\text { neurological illness } \\
\text { detected }\end{array}$ & $\begin{array}{l}\text { Died age } 12 \text { years of } \\
\text { pneumonia }\end{array}$ \\
\hline Brother & Diabetes mellitus & \\
\hline Sister & Pulmonary tuberculosis & \\
\hline Brother & $\begin{array}{l}\text { Died aged } 3 \text { years } \\
\text { ? cause }\end{array}$ & \\
\hline
\end{tabular}

In addition 2 sisters and 2 brothers healthy.

In June 1965 he developed blinking of his eyes, which gradually disappeared. The EEG was again within normal limits. During the autumn and winter of 1965 his parents and school teachers noticed a marked and progressive deterioration in his capabilities. Examples of writing from his school books are illustrated in Fig. 2. He had been a bright, friendly, active boy, whereas he was now slow and inattentive. He played very little with the other children, and he cried for no obvious cause. As the presenting features were of a personality disorder, the child psychiatrist, Dr. P. Barker, was asked to see him. He thought that he resembled a psychotic child in some respects, but that the underlying condition was most likely to be an organic brain disorder. In February 1966, careful clinical examination of the central nervous system still proved negative and his eyes were checked by Dr. A. Tulloch, the ophthalmologist, who found no abnormality. Detailed examination of the CSF was negative, but the EEG showed a severe degree of widespread slow wave abnormality, without focal or lateralizing features. There was no paroxysmal abnormality. The boy continued to deteriorate rapidly and in April he became blind. In other respects his central nervous system examination was negative and it was considered that he was suffering from a degenerative disorder, possibly Schilder's disease. The boy was investigated in Edinburgh where an air encephalogram in May 1966 showed cerebral atrophy with dilatation of the ventricles and no evidence of a space-occupying lesion. Dr. T. Ingram suggested 

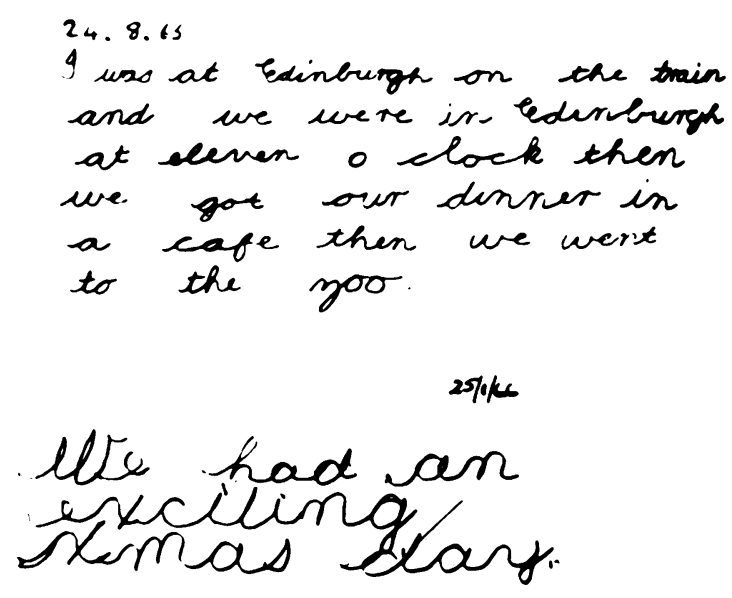

FIG. 2.-Samples of J.F.s writing on 24.8.65, 25.11.65, 25.1.66, and 17.2.66.

the diagnosis of Addison's disease combined with diffuse cerebral sclerosis. While the boy was in Edinburgh, Dr. W. Irvine tested for adrenal, thyroid, and gastric antibodies in him and his mother and some of her sibs, with negative results. The boy finally became spastic and incontinent, could no longer speak or feed himself, and behaved like a low grade mental defective (Fig. 3). He developed a terminal chest infection and died on 6 December 1966, three years after the diagnosis of Addison's disease was made and 13 months after the clinical onset of the neurological illness.

\section{Assays of Individual Urinary Steroids}

Assays of individual urinary steroids are being carried out in the Department of Child Health, University of Dundee, in a study of adrenocortical function in childhood. After extraction and hydrolysis, final separation and quantitation of the individual steroids is achieved by paper chromatography. Details of the method and of the results in 84 normal children and adolescents will be submitted for publication shortly.

The production of adrenal androgens before puberty is reflected by the excretion of dehydro-epi-androsterone (DHA), aetiocholanolone, and androsterone, that of cortisol by the excretion of tetrahydrocortisol (THF), allo-tetrahydrocortisol (allo-THF), and tetrahydrocortisone (THE), and that of corticosterone by the excretion of tetrahydrocorticosterone (THB), allotetrahydrocorticosterone (allo-THB), and tetrahydro11-dehydrocorticosterone (THA).

Six samples of the patient's urine were examined and the results compared with normal data from the laboratory expressed as the mean value for age and values for one and two standard deviations above and below the mean. The first sample was collected when he was ill
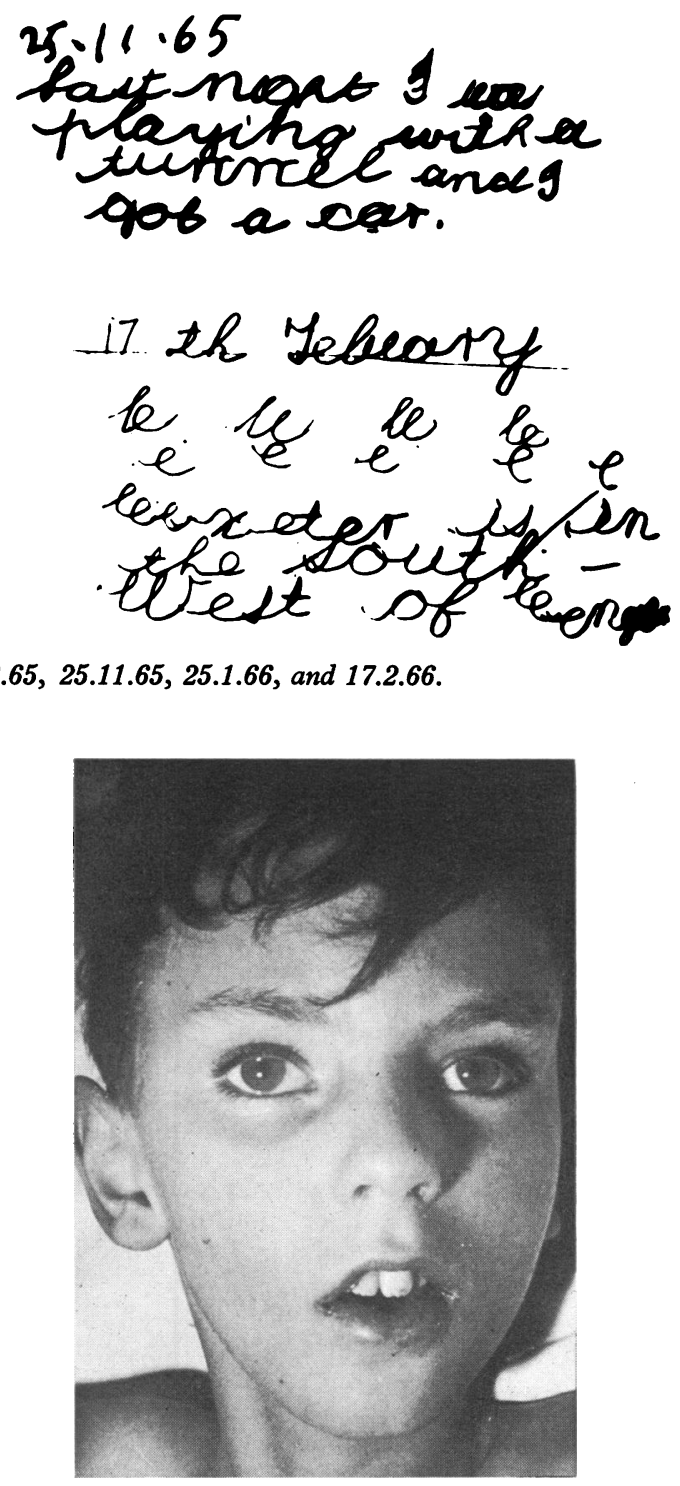

Fig. 3.-J.F. aged 9 years and 9 months.

on admission to hospital at the age of 7 years, the second when he was well before ACTH, and the third during the ACTH test. The fourth, fifth, and sixth samples were collected while he was on maintenance therapy with cortisone and fludrocortisone at the age of 9 years.

The six assays of 17-oxosteroids carried out according to an interim recommendation of a Medical Research Council Committee on Clinical Endocrinology (1963) gave values close to the mean in every instance, whereas the five assays of the sum of the individual estimations of 


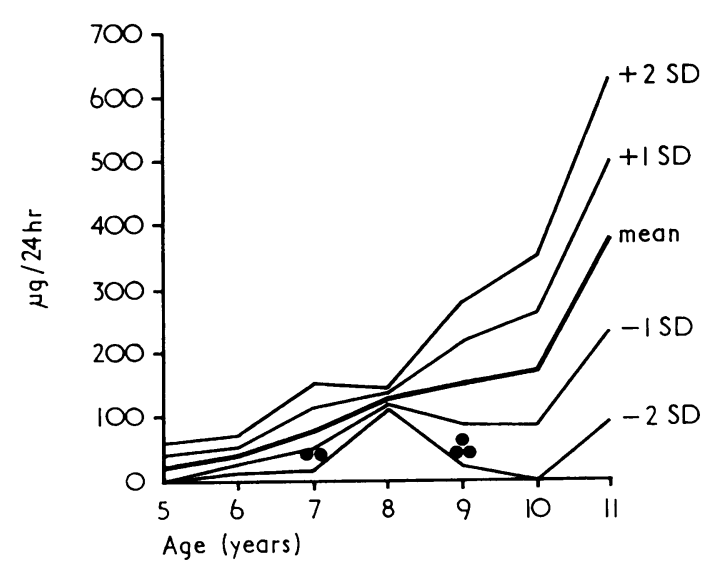

FIG. 4.-Urinary excretion of the sum of DHA, aetiocholanolone, and androsterone. $\quad=$ J.F. results.

DHA, aetiocholanolone, and androsterone fell consistently between 1 and 2 SD below the mean (Fig. 4).

The 17-hydroxycorticosteroid assay (Few, 1961) gave a high value, more than $2 \mathrm{SD}$ above the mean, in the first sample, reflecting a partial response to stress. The baseline result before ACTH was just below the mean, and there was no significant rise after ACTH. The total of the individual estimations of THF, alloTHF, and THE gave a result between 1 SD above the mean and the mean when he was ill and results between 1 and 2 SD below the mean before and during the ACTH test. The values at 9 years reflect the maintenance therapy (Fig. 5).

Further study of the patient's urine showed that it contained only traces of corticosterone metabolites, i.e. THB, allo-THB, and THA. These steroids are usually present in much greater quantity in the urine of normal children. No abnormal or unusual steroids were detected in any of the samples by the method in use.

\section{Pathology}

Necropsy was performed 4 hours after death.

Adrenals. The adrenals were in their normal anatomical position and they showed atrophy which was severe but not complete. The right adrenal weighed $1.9 \mathrm{~g}$ and the left adrenal $1.0 \mathrm{~g}$ (normal for 9 years $=$ $4.5 \mathrm{~g}$ each). In both glands there was apparent fibrous thickening of the capsule. Histologically, instead of the usual three layers, the cortex was replaced by nodules of large cells with eosinophilic, vacuolated cytoplasm (Fig. 6). There was variation in nuclear size and staining properties and an occasional multinucleate giant cell was present. Inflammatory infiltrate was very scanty, and in the multiple sections examined there was only a very occasional polymorph seen in the centre of a nodule and a few lymphocytes present in the capsule. Frozen sections stained for fat with Oil Red $O$ showed moderate accumulations of lipid in the cortical

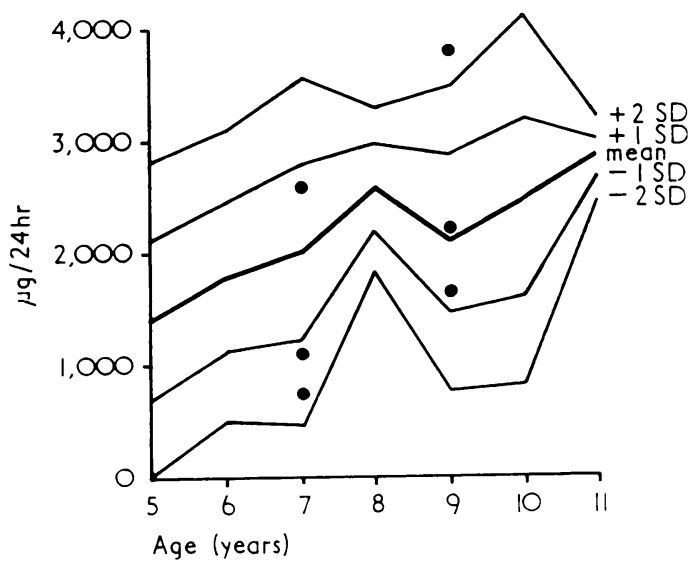

FIG. 5.-Urinary excretion of the sum of THF, allo$T H F$, and THE. $=$ J.F. results.

cells. The medulla appeared normal and the adrenal vessels showed no significant abnormality.

Pituitary. The pituitary gland including anterior and posterior lobes weighed $0.4 \mathrm{~g}$ (normal for 9 years $=$ $0.56 \mathrm{~g}$ ).

Eosinophil and chromophobe cells were present in normal numbers. Differential counts showed a marked increase in basophils and many were of the degranulated variety (Fig. 7).

Thyroid and parathyroids. These glands showed no abnormality.

Thymus. The thymus weighed $10 \mathrm{~g}$ (normal for 9 years $=26 \mathrm{~g}$ ).

There was atrophy of the cortex with depletion of lymphocytes and replacement by fibro-fatty tissue. The medulla showed normal medullary cells, plasma cells, and eosinophils. Hassell's corpuscles were large, necrotic, and many were calcified. Germinal centres were absent. No Russell bodies were seen.

Pancreas. The pancreas showed no abnormality.

Testes. Each testis weighed $3.6 \mathrm{~g}$.

There was a reduction in the number of spermatogonia compared to testes from normal boys of nine years. The Leydig cells were normal.

Brain. The brain weighed $1300 \mathrm{~g}$ (normal for 9 years $=1800 \mathrm{~g}$ ) and showed no external abnormality. On serial coronal sectioning there was a large, firm, grey zone of demyelination involving the central and convolutional white matter of each hemisphere. The lesions extended from the occipital poles forwards into the temporal and parietal lobes (Fig. 8). Their margins were sharply defined and apparently limited by the arcuate fibres. They did not involve the internal 


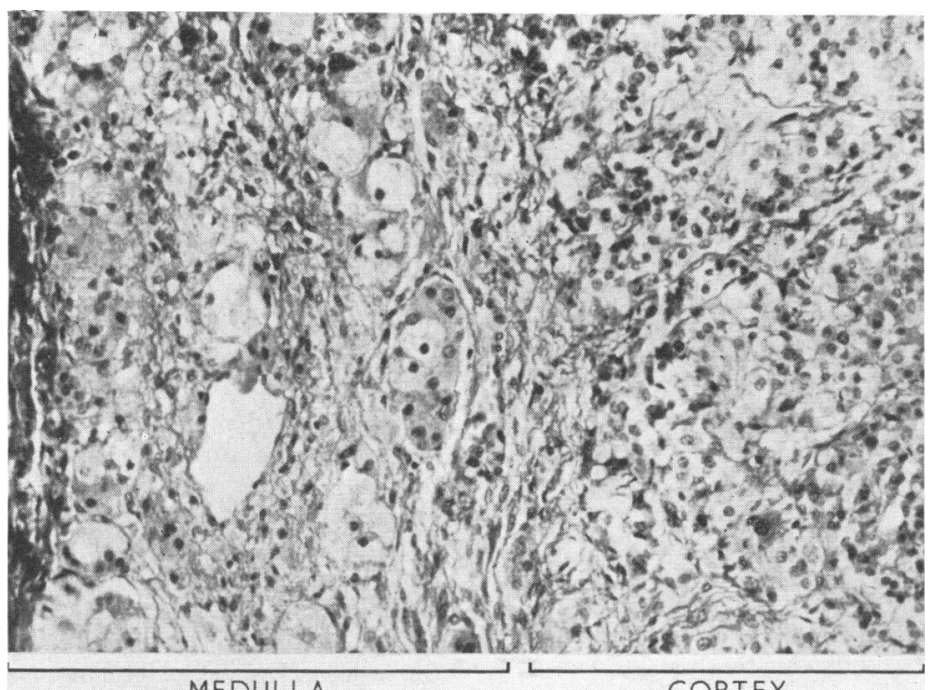

MEDULLA

CORTEX

FIG. 6.-Adrenal: showing cortical atrophy with large vacuolated cells and relative prominence of medulla. (Haematoxylin and van Gieson. $\times 165$.

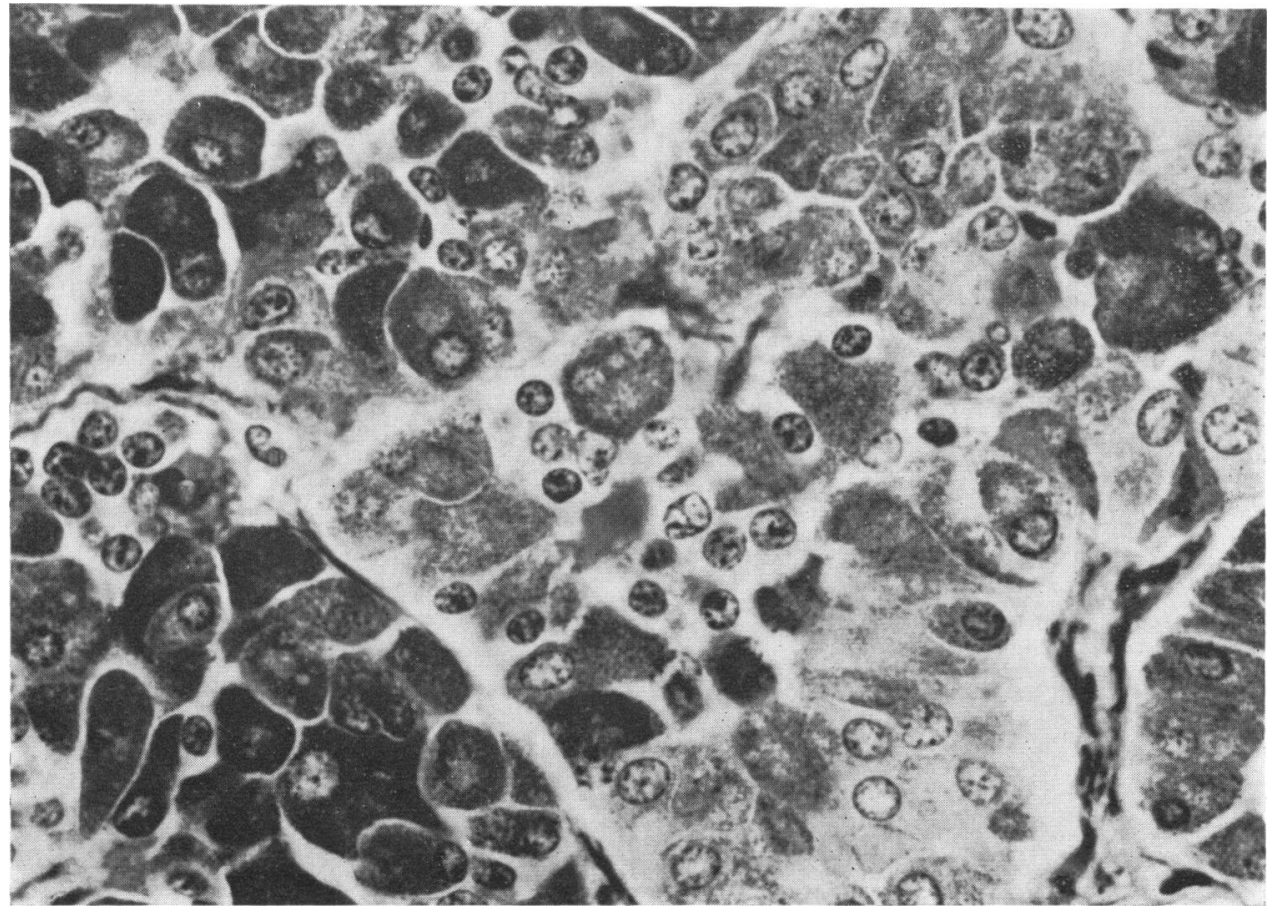

FIG. 7.-Pituitary: an area of basophils showing various stages of degranulation. (Slidders O.F.G. $\quad \times \quad 835$.) 


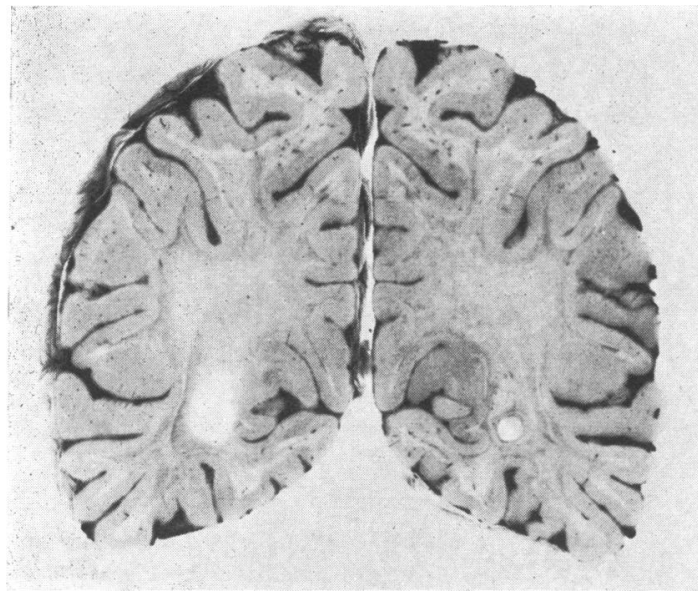

FIG. 8.-Occipital poles: showing extensive gelatinous area of demyelination.

capsules, cortical grey matter, or basal ganglia, and these structures together with the white matter of the frontal lobes appeared normal. The lateral and third ventricles were moderately dilated. Sections of brain-stem showed ill-defined greyish discoloration of the cerebral peduncles and pyramids. The cerebellum, aqueduct, and fourth ventricle were normal. The spinal cord also appeared normal.

Representative blocks were taken from the lesions and the normal areas of cerebral hemisphere, the basal ganglia, brainstem, and spinal cord. Frozen sections were stained with Oil Red $O$ and Sudan Black for fats, by Holzer's method for glial fibres, by toludine blue for metachromasia, and by Bielschowsky's method for axons and neurofibrils. Paraffin and low viscosity nitro- cellulose (LVN) sections were stained with haematoxylin and eosin (H and E), period acid-Schiff (PAS), phosphotungstic acid haematoxylin (PTAH), solochrome cyanin, and by Woelcke's method for myelin and Holmes' method for axis cylinders.

Cerebrum. Sections from the large lesions noted in the posterior half of each hemisphere confirmed that there were extensive zones of demyelination and they all showed similar histological features. In the central parts demyelination was complete and of some standing (Fig. 9). As shown in the Bielschowsky preparation, there was a reduction in the number of axons and the surviving ones were often swollen and beaded. There was dense fibrillary gliosis and many of the astrocytes were large with plump cytoplasm and large atypical nuclei. Sporadically, the multinucleate oligodendrocytes were greatly reduced in number. Cerebral histiocytes were seen mainly in perivascular spaces, but small numbers were scattered throughout the lesions (Fig. 10). The material in these cells stained positively with Sudan Black and Oil Red O (Fig. 11) and contained PAS positive granules. There was no metachromasia. The vessels were increased in size and apparently in number, and most showed perivascular cuffing with lymphocytes and plasma cells in addition to the histiocytes already noted (Fig. 10). At the margins of the lesions the demyelination appeared to be still active. The surviving myelin sheaths were swollen, ballooned, and fragmented, histiocytes were more numerous, and perivascular infiltration was more severe. The subcortical white matter (arcuate fibres) appeared to be spared on the whole, but in some sections the degenerative process extended into it and encroached on the lower layers of the cortex. A small demyelinating focus with similar histological features was found in part of one optic tract. In some sections of cortex there

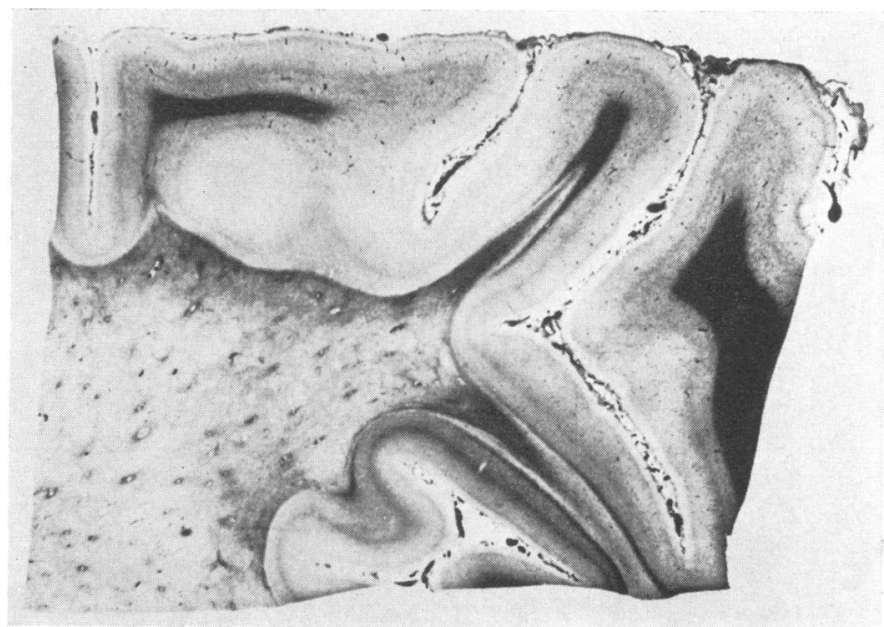

FIG 9.-Section from occipital region: complete demyelination of central white matter extending to arcuate fibres. (Woelcke myelin stain. $\times 4$.) 


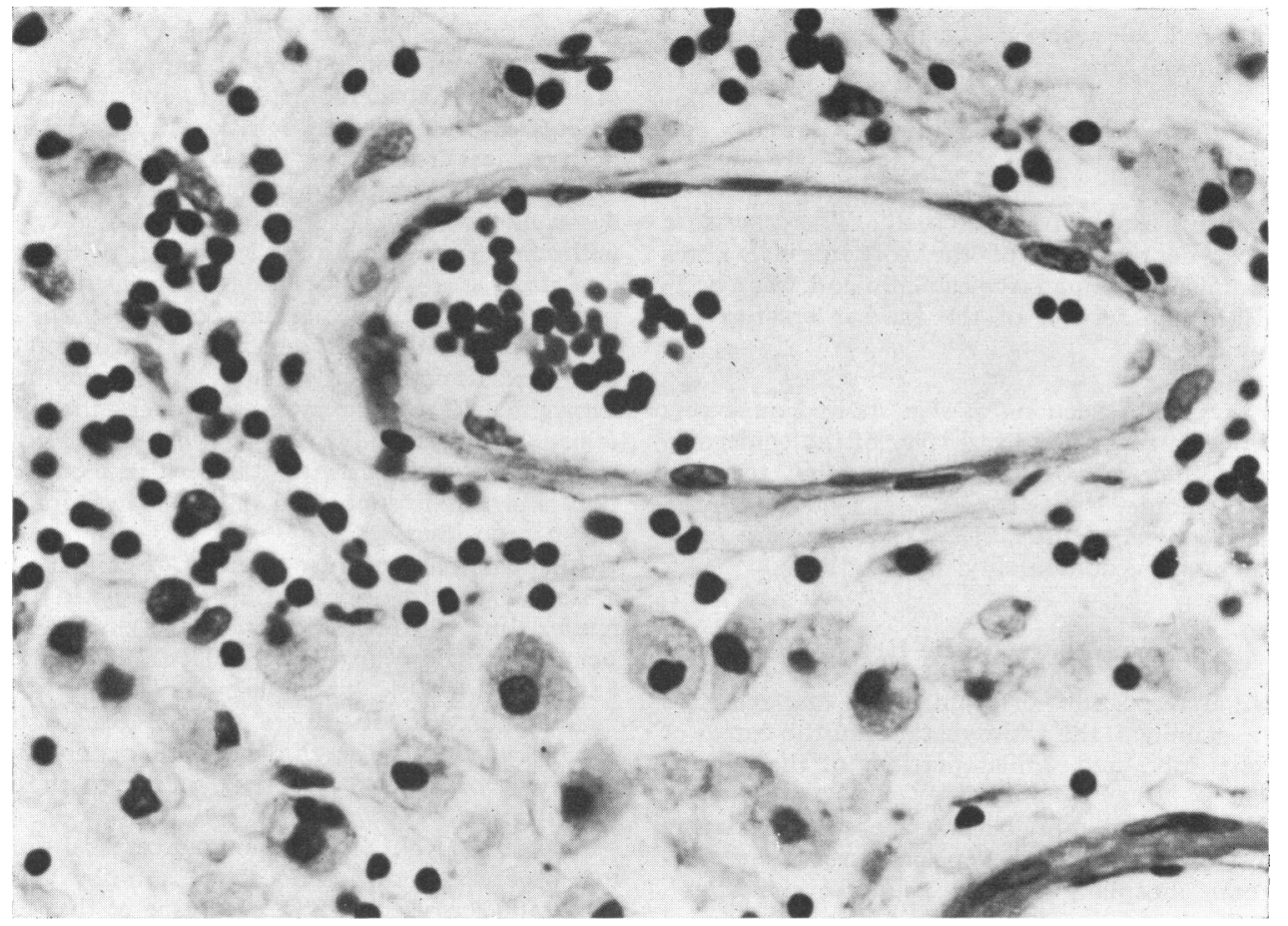

FIG. 10.-Perivascular cuffing with histiocytes, lymphocytes and plasma cells. (Haematoxylin and eosin. $\quad \times 670$.)

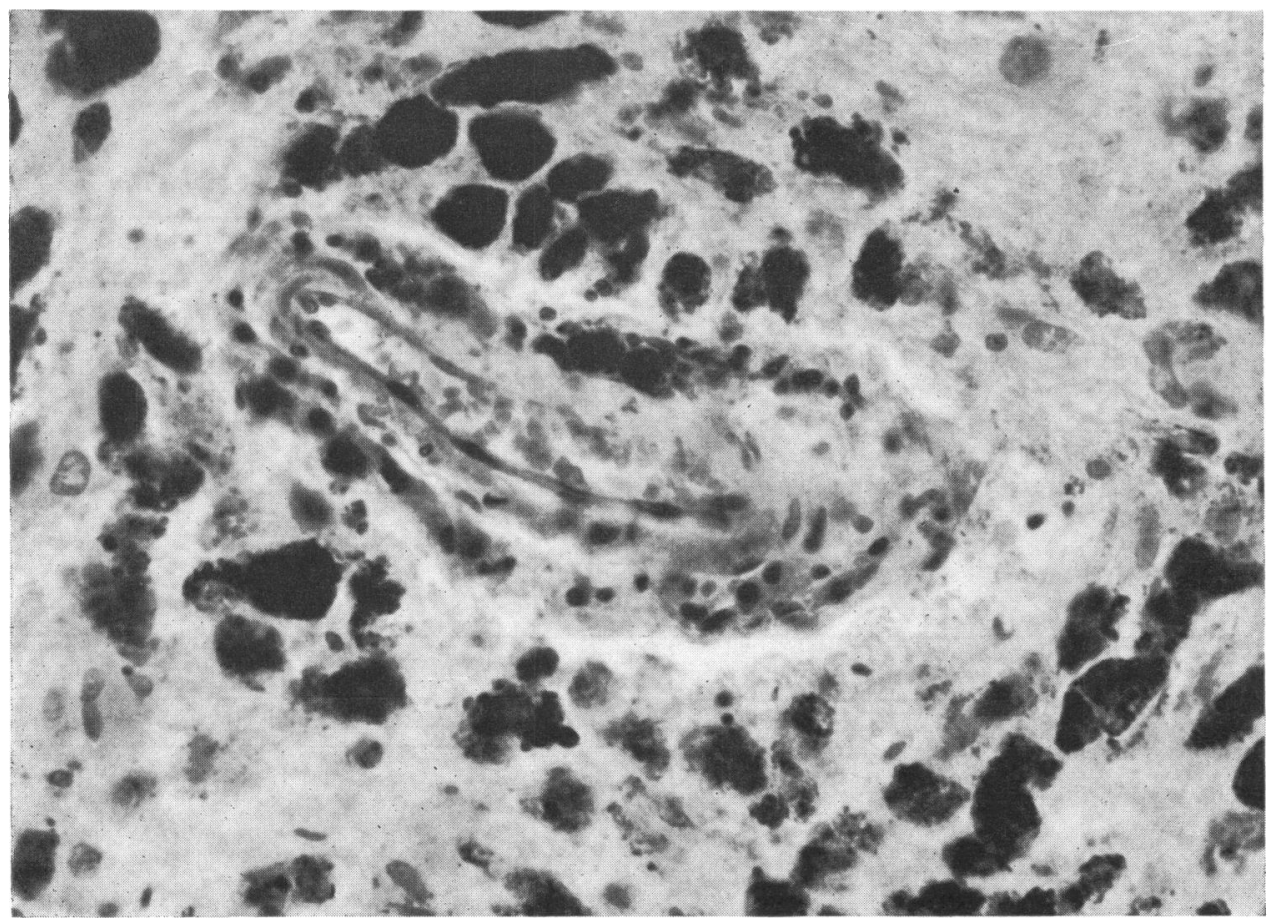

FIG. 11.-Neutral fat in histiocytes. (Oil Red $O$ and haematoxylin. $\times 500$. 
was a mild red cell reaction but the grey matter was essentially normal.

Cerebellum. The cerebellum showed no abnormalities.

Brainstem and spinal cord. There was a symmetrical degeneration of the corticospinal fibres which diminished in intensity caudally and was barely detectable in the section of the lumbar enlargement of the spinal cord.

Other organs. Sections of skin showed an excess of melanin pigment in the basal layer of the epidermis. Sections of lung showed the changes of terminal bronchopneumonia.

Routine sections of liver, spleen, kidneys, and bonemarrow showed no abnormality.

\section{Biochemistry of the Brain}

Four separate portions of brain of the case recorded here were examined, the white matter and the cortex of the occipital lobe, and similar portions of the parietal lobe.

Water content of all four areas was measured by drying a small amount of wet tissue in vacuo at room temperature. Total phospholipid, total and free cholesterol, total hexosamine and neuraminic acid were estimated as previously (Cumings and Rozdilsky, 1965). Total galactoside determinations were performed by the method of Svennerholm (1956) with the hydrolysis procedure of Radin, Brown, and Lavin (1956).

Thin layer chromatography (TLC) was performed by the technique of Müldner, Wherrett, and Cumings (1962) for phospholipids, sphingolipids, and gangliosides, and with the methods of Brown and Johnston (1962) and Freeman and West (1966) for cholesterol and triglycerides.

The results are shown in Table II. The only abnormality present in the white matter of the parietal lobe is a slight increase in esterified cholesterol. The occipital white matter shows a considerable reduction in phospholipids and cerebrosides and an increase in esterified cholesterol. These findings were also very obvious in the TLC plates, in which the loss of cere- broside and sulphatide was especially obvious. The cerebral cortex from both areas showed reduced levels of lipids with considerable excess of esterified cholesterol. The ganglioside patterns seen by TLC were normal in both cortical areas.

The striking features present were evidence of active demyelination in the occipital white matter together with changes in the cerebral cortex in which not only was there a general loss of total galactosides and of phospholipids, but also an increase of esterified cholesterol which is normally absent. It is of interest that total hexosamine is only slightly raised in the grossly demyelinated white matter. In a case recently described (Menkes and Eviatar, 1969) cholesterol esters were present together with other evidence of demyelination, and this is supported in the analysis of the fatty acid composition.

In sudanophilic diffuse sclerosis ('Schilder's disease') a similar picture is seen biochemically in the white matter, but with a raised total hexosamine, the cortex being virtually unaffected (Dyck, Cumings, and Olszewski, 1960). There are changes in both white matter and cortex in Alpers' disease (Blackwood et al., 1963), but neither the clinical condition nor the histopathology of Alpers' disease is similar to those of the present case.

One of us (J.N.C.) has examined cerebral tissue from two other cases of adrenocortical atrophy and diffuse cerebral sclerosis in males, and some of the results are recorded in Table III; it is seen that there is a wellmarked abnormality in the cortex as well as demyelination in the white matter.

TABLE III

Cerebral Lipids ( $\mathrm{g} / 100 \mathrm{~g}$ dry tissue) in 2 Other Cases

\begin{tabular}{l|r|r|r|r}
\hline & \multicolumn{2}{|c|}{ Male 11 years } & \multicolumn{2}{c}{ Male 9 years } \\
\cline { 2 - 5 } & White & Cortex & White & Cortex \\
\hline Total phospholipid & $17 \cdot 6$ & $22 \cdot 0$ & $7 \cdot 6$ & $18 \cdot 7$ \\
Total cholesterol & $5 \cdot 2$ & $4 \cdot 5$ & $8 \cdot 5$ & $5 \cdot 7$ \\
Esterified cholesterol & $2 \cdot 3$ & $1 \cdot 7$ & $5 \cdot 3$ & $1 \cdot 4$ \\
Total galactosides & $6 \cdot 3$ & $2 \cdot 8$ & $1 \cdot 4$ & $2 \cdot 6$ \\
Water (\%) & $84 \cdot 1$ & $84 \cdot 5$ & $80 \cdot 1$ & $85 \cdot 5$ \\
& & & & \\
\hline
\end{tabular}

TABLE II

Cerebral Lipids (g/100 g dry tissue) in J.F. Aged 9 Years

\begin{tabular}{|c|c|c|c|c|c|c|}
\hline & \multicolumn{2}{|c|}{ Normal Values } & \multicolumn{2}{|c|}{ Parietal Lobe } & \multicolumn{2}{|c|}{ Occipital Lobe } \\
\hline & White & Cortex & White & Cortex & White & Cortex \\
\hline $\begin{array}{l}\text { Total phospholipid } \\
\text { Total cholesterol } \\
\text { Esterified cholesterol } \\
\text { Total galactosides } \\
\text { Total hexosamine } \\
\text { N acetyl neuraminic acid } \\
\text { Water }(\%)\end{array}$ & $\begin{array}{c}22-24 \\
12-14 \\
0 \cdot 4 \\
12-15 \\
0 \cdot 3 \\
72-75\end{array}$ & $\begin{array}{c}20-22 \\
6-8 \\
0 \\
3-5 \\
0 \cdot 7 \\
0 \cdot 3 \\
80-83\end{array}$ & $\begin{array}{r}23 \cdot 7 \\
13 \cdot 4 \\
2 \cdot 6 \\
20 \cdot 9 \\
0 \cdot 3 \\
72 \cdot 6\end{array}$ & $\begin{array}{r}17 \cdot 7 \\
5 \cdot 5 \\
1 \cdot 0 \\
2 \cdot 2 \\
0 \cdot 6 \\
0 \cdot 3 \\
82 \cdot 8\end{array}$ & $\begin{array}{r}14 \cdot 9 \\
5 \cdot 4 \\
1 \cdot 6 \\
3 \cdot 5 \\
0 \cdot 4 \\
84 \cdot 3\end{array}$ & $\begin{array}{r}14 \cdot 2 \\
5 \cdot 4 \\
0 \cdot 7 \\
3 \cdot 7 \\
0 \cdot 5 \\
0 \cdot 3 \\
81 \cdot 4\end{array}$ \\
\hline
\end{tabular}




\section{Discussion}

The combined syndrome of Addison's disease and diffuse cerebral sclerosis was diagnosed on clinical grounds, and the findings at necropsy in the adrenal glands and the central nervous system were similar to those described in the well-documented cases in the literature. Skin pigmentation was present for four years before any other manifestations of Addison's disease were noted and the neurological disorder presented as a personality change with progressive intellectual deterioration for at least six months before visual impairment developed. Spasticity followed several months later.

From the detailed studies of the excretion of adrenal steroids it was evident that the more definitive method of determining the androgens and the tetrahydro metabolites of cortisol and corticosterone individually by paper chromatography revealed the diminution in excretion due to adrenocortical atrophy much more clearly than the routine assays of 17-oxosteroids and 17-hydroxycorticosteroids, though it was possible to make the diagnosis by a failure of response to ACTH using the latter assay. Gray (1969) gives a brief comment on the examination of one 24-hour urine collection from an adult patient with Addison's disease and diffuse cerebral sclerosis made under ACTH stimulation. M. Damkjaer Nielsen (1970, personal communication), who carried out the assays, reported an excretion of cortisol metabolites normal for the resting state but low for an ACTH stimulated subject, and zero excretion of corticosterone metabolites. She had found zero excretion of corticosterone metabolites only once previously in 1 of 12 patients with Addison's disease in the resting state, and this patient had a very low excretion of cortisol metabolites as well. In other patients with Addison's disease corticosterone metabolites were found in the normal proportion in comparison with cortisol metabolites. No abnormal steroids were found in Gray's patient. The androgen excretion was not investigated. Cost (1963) reported a relatively greater reduction in the excretion of corticosterone metabolites than of cortisol metabolites in 4 out of 6 adults with untreated Addison's disease, and he suggested that this was because endogenous ACTH stimulated the cortisol pathway preferentially. He did not comment on the excretion of androgens in his patients. It is recognized that adrenal androgens probably play a part in the physiological stimulation of growth and skeletal maturation in childhood and adolescence (Hubble, 1969), but the depression of adrenal function was not complete in our patient and the boy's growth and skeletal maturation were normal.
No adrenal antibodies could be detected in the serum either during life or in post-mortem blood. The adrenal histology had features in common with the idiopathic cortical atrophy seen in adult Addison's disease and the paucity of inflammatory infiltrate was thought not necessarily to exclude an autoimmune aetiology (T. Symington, 1968, personal communication). Blaw et al. (1964), Turkington and Stempfel (1966), and Gordon and Marsden (1966) pointed out the absence of inflammatory infiltration in their cases. In the literature on the combined syndrome there have been no instances of tuberculosis of the adrenal glands. Uttley (1968) suggested that the development of Addison's disease in childhood might be a late manifestation of congenital adrenal hypoplasia. However, the histology of the adrenal glands in our patient bore no resemblance to either the 'anencephalic' or the 'cytomegalic' type of abnormality seen in congenital hypoplasia.

The pathological changes in the anterior pituitary gland were compatible with those found in a primary disorder of the adrenal glands but differed from those described in the literature of Addison's disease and diffuse cerebral sclerosis, in that there was an overall increase in degranulated basophils which amounted to twice the normal number for a child of 9 years (Rasmussen, 1950). However, a high proportion of degranulated basophils is usual in the pituitary in Addison's disease in adults. The thyroid was entirely normal in our patient as in the reports on the combined syndrome, whereas $50 \%$ of adults with Addison's disease have abnormalities of the thyroid (Sloper, 1955). There was also no abnormality of the parathyroid glands. The thymus showed involutionary changes related to a variety of factors, for example age, prolonged illness and steroid administration. Dubois et al. (1964), and Turkington and Stempfel (1966) mention the thymus in their reports and describe similar changes to those found in our patient. The pancreas was normal. The pathological changes in the testes were minimal and of doubtful significance in isolation, but when compared with the descriptions of impaired development in the reports of Fanconi et al. (1963) and Hoefnagel et al. (1967) there may have been a degree of hypogonadism. The boy described by Hoefnagel et al. in $1962 \mathrm{had}$ an interstitial cell tumour of one testis. The Leydig cells, which produce testosterone, were normal in our case.

The changes in the brain of diffuse demyelination, gliosis, and sudanophilia found in our case have been reported in the literature on combined Addison's disease and diffuse cerebral sclerosis. 
We found a variable distribution of areas of demyelination, axon degeneration, and PAS-positive staining. Metachromatic material was not demonstrated and has not been reported in any of the other cases. Very minimal changes were observed in the U fibres and Dubois et al. (1964) and Hoefnagel et al. (1967) also reported some involvement. The grey matter in our case was essentially normal on histological examination, but the biochemical study of the brain revealed unequivocal changes in the cerebral cortex as well as those of demyelination in the white matter, favouring a diagnosis of diffuse cerebral sclerosis rather than 'Schilder's disease'. Both the reports of Hoefnagel et al. indicated histological abnormalities in the grey matter. In their paper of 1962 the index case was described as showing glial heterotopias in the cerebral cortex. Their 1967 report described scattered demyelinating lesions affecting $U$ fibres and extending into the deeper layers of the cortex.

As mentioned in the introductory paragraph there are 12 fully documented reports in the literature of boys with the combination of Addison's disease and diffuse cerebral sclerosis, as well as the two boys reported in whom the pathological data are incomplete. Usually, as in our patient, the Addison's disease was diagnosed first but in some the disorder of the nervous system was recognized but the significance of the skin pigmentation was not appreciated during life, there being no other clinical signs of Addison's disease.

Several hypotheses have been put forward to explain the combination of adrenal and brain disease as the association of the two in boys has been described too often to be due to coincidence. Some writers have considered that the Addison's disease was secondary to anterior pituitary damage. However, the presence of skin pigmentation reflects increased anterior pituitary activity, and the pathological findings in the literature and in our case do not support the concept of primary hypofunction of the anterior pituitary gland. Others have thought that the diffuse cerebral sclerosis was secondary to Addison's disease; for example, Blaw et al. (1964) postulated that the adrenal glands might produce an abnormal steroid toxic to the central nervous system, and suggested that detailed chromatography of the urine would be of value. In our patient the assays of individual urinary steroids showed a diminished production of adrenal androgens and corticosteroids in the resting state and failure of a normal corticosteroid response to stress and ACTH stimulation, but the steroids excreted were the same as those of normal boys and no unusual or unknown steroids were detected.
We have therefore produced no evidence to support their hypothesis.

Adrenocortical atrophy with diffuse cerebral sclerosis might be due to an error of metabolism common to the adrenal cortex and the brain. Though no evidence of an adrenal enzyme deficiency leading to an diminished production of androgens and corticosteroids was found, an abnormality of metabolism in relation to the cholesterol stage of synthesis remains a theoretical possibility. Such an error could also cause a diminution of testosterone production in the testes. The biochemical studies of brain tissue in our patient revealed abnormal proportions of brain lipids and cholesterol. Menkes and Eviatar (1969) reported an abnormal sterol with the same number of carbon atoms as cholesterol in the white matter of the brain in a case of the combined syndrome. It is therefore at least possible that an abnormality of sterol metabolism in relation to cholesterol might cause the cerebral sclerosis. Histochemical, biochemical, and tissue culture studies of adrenal and brain tissue in other patients in the future should lead to a fuller understanding of the nature of the condition.

Finally, the possibility that both conditions are due to atrophy of tissue cells due to an underlying autoimmune disorder requires consideration. The occurrence of disease in other endocrine glands in patients with Addison's disease is well recognized (Wilkins, 1965; Visser, 1969; Cathro, 1969). However, the connexion between adrenal disease and brain disease is more speculative. Adrenal atrophy has been found uniformly at necropsy, but in no case have circulating antibodies to adrenal tissue been demonstrated, nor has any evidence been found for a possible autoimmune basis for the cerebral sclerosis in the combined syndrome. We arranged for studies by direct immunofluorescence to be made in another laboratory, but, unfortunately, the fresh frozen adrenal and brain tissues were lost. Thyroid disease has not been described in the combined condition but testicular atrophy has been reported. In our patient, circumstantial evidence in favour of an autoimmune basis for the Addison's disease is shown in the family history of autoimmune disorders in the mother's sibs. In studies of Addison's disease due to adrenal atrophy by Irvine, Stewart, and Scarth (1967) and Blizzard, Chee, and Davis (1967) the following conditions have been noted in close relatives-hyperthyroidism, hypothyroidism, hypoparathyroidism, diabetes mellitus, pernicious anaemia, atrophic gastritis, and rheumatoid arthritis. In the series of Irvine $e t$ al. (1967) circulating adrenal antibodies were detected 
in $80 \%$ of the female patients and $10 \%$ of the male patients. In a review, British Medical Journal (1969), substantial evidence is given for autoimmune basis for Addison's disease with adrenocortical atrophy. The possibility of other varieties of familial adrenal deficiency due to enzyme defects is also mentioned. There is some less well-documented evidence for an autoimmune basis for multiple sclerosis in adults, for example Lamoureux and Borduas (1966) have detected cytotoxic antibodies to brain tissue in the serum and CSF of patients with multiple sclerosis, correlating with the increase in $\gamma$-globulin in the CSF during the acute stage, and Zilkha (1968) in a review of multiple sclerosis gives prominence to the autoimmune hypothesis.

Autoimmune disease of the adrenal glands is commoner in females than males and multiple sclerosis of the brain affects females as well as males. As the combined condition of adrenocortical atrophy and diffuse cerebral sclerosis occurs only in males, it is likely that it is a separate entity, and, from a consideration of the literature, that it is inherited as an X-linked recessive characteristic. Hoefnagel et al. (1962) referred to a brother of their patient with adrenal atrophy confirmed at necropsy. Blaw et al. (1964) reported a maternal uncle of their patient with sudanophilic leucodystrophy at necropsy, and Dubois et al. (1964) reported a maternal cousin of their patient with Schilder's disease diagnosed clinically. The sex was not stated. Our boy's maternal uncle had Addison's disease. These reports might represent instances of the combined syndrome though the other manifestation was not noted. The history of autoimmune disorders on the mother's side of the family shown in our patient is more striking than in the literature on the combined syndrome in boys, though similar to that given in a report of two brothers in adult life with Addison's disease and what was termed spastic paraplegia. No necropsy studies were made in these cases. A family history of autoimmune disorders included their mother with pernicious anaemia, their brother with diabetes mellitus, and their sister with rheumatoid arthritis (Harris-Jones and Nixon, 1955). In a recent clinical report of a man of 26 years with Addison's disease and diffuse cerebral sclerosis (Gray, 1969), it is recorded that an older brother died of diffuse cerebral sclerosis. There was no clinical evidence of Addison's disease, and the adrenal glands were not examined in detail at necropsy. Further study of the family histories of future patients is required to clarify the possible relation of a general endocrine autoimmune disease background to the specific entity of adrenocortical atrophy and diffuse cerebral sclerosis.

In addition to those named in the text, we wish to thank Dr. A. F. J. Maloney for help with the pathology and Mr. R. Fawkes for the histological preparations and photomicrography. The assays of individual steroids were done by Mrs. J. Cameron and Miss E. McCafferty under a scheme supported by the Medical Research Council.

REFERENCES

Adams, R. D., and Kubik, C. S. (1952). The morbid anatomy of the demyelinative diseases. American fournal of Medicine, $12,510$.

Blackwood, W., Buxton, P. H., Cumings, J. N., Robertson, D. J., and Tucker, S. M. (1963). Diffuse cerebral degeneration in infancy (Alpers' disease). Archives of Disease in Childhood, $38,193$.

Blaw, M. E., Osterberg, K., Kosak, P., and Nelson, E. (1964). Sudanophilic leukodystrophy and adrenal cortical atrophy. Archives of Neurology, 11, 626.

Blizzard, R. M., Chee, D., and Davis, W. (1967). The incidence of adrenal and other antibodies in the sera of patients with idiopathic adrenal insufficiency. Clinical and Experimental Immunology, 2, 19.

British Medical fournal (1969). Immunological aspects of Addison's disease. Leading article. 4, 382.

Brown, J. L., and Johnston, J. M. (1962). Radioassay of lipid components separated by thin-layer chromatography. Fournal of Lipid Research, 3, 480.

Brun, A., and Voigt, G. E. (1960). Entzündliche cerebrale Sklerose mit Nebenniereninsuffizienz. Deutsche Zeitschrift für Nervenheilkunde, 180, 654.

Cathro, D. M. (1969). In Paediatric Endocrinology, p. 279. Ed. by D. Hubble. Blackwell, Oxford.

Clayton, B. E., Edwards, R. W. H., and Renwick, A. G. C. (1963). Adrenal function in children. Archives of Disease in Childhood, $33,49$.

Cost, W. S. (1963). Quantitative estimation of adrenocortical hormones and their $\alpha$-ketolic metabolites in urine. III. Adrenocortical hypofunction. Acta Endocrinologica (Copenhagen), 42, 53.

Cumings, J. N., and Rozdilsky, B. (1965). The cerebral lipid composition of the brain in 6 cases of Krabbe's disease. Neurology (Minneapolis), 15, 177.

Dubois, R., Loeb, H., Périer, O., Parmentier, R., and Szliwowski, H. (1964). Maladie d'Addison et sclérose diffuse de Schilder. Helvetica Paediatrica Acta, 19, 528.

Dyck, P. J., Cumings, J. N., and Olszewski, J. (1960). Sudanophilic leukodystrophy with increased hexosamine content. Neurology (Minneapolis), 10, 765.

Fanconi, A., Prader, A., Isler, W., Lüthy, F., and Siebenmann, R. (1963). Morbus Addison mit Hirnsklerose im Kindesalter. Helvetica Paediatrica Acta, 18, 480.

Few, J. D. (1961). A method for the analysis of urinary 17hydroxycorticosteroids. Fournal of Endocrinology, 22, 31.

Freeman, C. P., and West, D. (1966). Complete separation of lipid classes on a single thin-layer plate. fournal of Lipid Research, 7, 324.

Gagnon, J., and Leblanc, R. (1959). Sclérose cérébrale diffuse avec mélanodermie et atrophie surrénale. Union médicale $d u$ Canada, 88, 392.

Gordon, N., and Marsden, H. B. (1966). Diffuse cerebral sclerosis and adrenal atrophy. Developmental Medicine and Child Neurology, 8, 719

Gray, A. M. (1969). Addison's disease and diffuse cerebral sclerosis. fournal of Neurology, Neurosurgery, and Psychiatry, 32, 344.

Harris-Jones, J. N., and Nixon, P. G. F. (1955). Familial Addison's disease with spastic paraplegia. Fournal of Clinical Endocrinology, 15, 739.

Hoefnagel, D., Brun, A., Ingbar, S. H., and Goldman, H. (1967). Addison's disease and diffuse cerebral sclerosis. fournal of Neurology, Neurosurgery, and Psychiatry, 30, 56. 
Hoefnagel, D., Van den Noort, S., and Ingbar, S. H. (1962). Diffuse cerebral sclerosis with endocrine abnormalities in young males. Brain, 85, 553.

Hubble, D. (1969). Paediatric Endocrinology, p. 18. Blackwell, Oxford.

Irvine, W. J., Stewart, A. G., and Scarth, L. (1967). A clinical and immunological study of adrenocortical insufficiency (Addison's disease). Clinical and Experimental Immunology, 2, 31 .

Lamoureux, G., and Borduas, A. G. (1966). Immune studies in multiple sclerosis. Clinical and Experimental Immunology, 1, 363.

Lichtenstein, B. W., and Rosenbluth, P. R. (1959). Schilder's disease with melanoderma. Fournal of Neuropathology and Experimental Neurology, 18, 384.

Medical Research Council Committee on Clinical Endocrinology (1963). A standard method of estimating 17-oxosteroids and total 17-oxogenic steroids. An Interim Recommendation. Lancet, 1, 1415.

Menkes, J. H., and Eviatar, L. (1969). Abstract No. 50 from the Meeting of the American Pediatric Society and the Society for Pediatric Research, 3 May 1969. Pediatric Research, 3, 359.

Müldner, H. G., Wherrett, J. R., and Cumings, J. N. (1962). Some applications of thin-layer chromatography in the study of cerebral lipids. Fournal of Neurochemistry, 9, 607.

Pfister, R. (1936). Beitrag zur Kenntnis der diffusen Hirnsklerose. Archiv für Psychiatrie und Nervenkrankheiten, 105, 1.

Radin, N. S., Brown, J. R., and Lavin, F. B. (1956). The preparative isolation of cerebrosides. Fournal of Biological Chemistry, $219,977$.

Rasmussen, A. T. (1950). Changes in the proportion of cell types in the anterior lobe of the human hypophysis during the first nineteen years of life. American fournal of Anatomy, 86, 75 .

Siemerling, E., and Creutzfeldt, H. G. (1923). Bronzekrankheit und sklerosierende Encephalomyelitis (Diffuse Sklerose). Archiv für Psychiatrie und Nervenkrankheiten, 68, 217.

Sloper, J. C. (1955). The pathology of the adrenals, thymus and certain other endocrine glands in Addison's disease: an analysis of 37 necropsies. Proceedings of the Royal Society of Medicine, 48, 625 .

Svennerholm, L. (1956). The quantitative estimation of cerebrosides in nervous tissue. Fournal of Neurochemistry, 1, 42.

Turkington, R. W., and Stempfel, R. S., Jr. (1966). Adrenocortical atrophy and diffuse cerebral sclerosis (Addison-Schilder's disease). Fournal of Pediatrics, 69, 406.

Uttley, W. S. (1968). Familial congenital adrenal hypoplasia. Archives of Disease in Childhood, 43, 724.

Visser, H. K. A. (1969). In Endocrine and Genetic Diseases of Childhood, ed. by L. I. Gardner, p. 454. Saunders, Philadelphia and London.

Wilkins, L. (1965). The Diagnosis and Treatment of Endocrine Disorders in Childhood and Adolescence, 3rd ed., p. 372. Charles C. Thomas, Springfield, Illinois.

Zilkha, K. J. (1968). Review of Multiple Sclerosis. Biochemical Aspects of Neurological Disorders, 3rd series, p. 37. Ed. by J. N. Cumings and M. Kremer. Blackwell, Oxford.

Correspondence to Dr. Constance C. Forsyth, Department of Child Health, University of Dundee, 11 Dudhope Terrace, Dundee DD3 6HG. 